\title{
PERUMUSAN STRATEGI BISNIS BLUEPRINT INSTITUT TEKNOLOGI TELKOM PURWOKERTO DENGAN ANALISIS SWOT
}

\author{
Dwi Mustika Kusumawardani ${ }^{1)}$ \\ 1) Institut Teknologi Telkom Purwokerto \\ Jl. D. I. Panjaitan No. 128, Purwokerto, Indonesia \\ ${ }^{1)}$ dwimustika@ittelkom-pwt.ac.id
}

\begin{abstract}
Pembuatan blueprint merupakan satu hal yang perlu diperhatikan dalam pengembangan mutu suatu institusi. Mengapa ITTP perlu melakukan hal tersebut? Hal tersebut perlu dilakukan agar ITTP dapat menghadapi persaingan yang semakin kompetitif dengan mengenali faktor - faktor internal yang dimiliki. Blueprint ITTP dapat dibuat menggunakan analisis SWOT dalam menentukan strategi bisnisnya. Analisis SWOT dilakukan dengan mengumpulkan data dan menganalisis semua unit yang terlibat dalam proses bisnis ITTP. Hasil dari blueprint ITTP yang dilakukan dengan menggunakan analisis SWOT dapat diketahui bahwa ITTP memiliki peluang yang besar dengan ancaman yang pasti dapat diatasi dengan mengadakan upgrading pelatihan ISO dan standar - standar lainnya. Selain itu dapat juga diatasi dengan terus mengembangkan teknologi sistem informasi dengan memanfaatkan IT Support yang dimiliki ITTP.
\end{abstract}

Keyword: Blueprint, Pendidikan, SWOT Analysis, Strategi Bisnis

\section{INTRODUCTION}

Pemanfaatan teknologi informasi saat ini dapat ditemukan diberbagai bidang, salah satunya ada dalam dunia pendidikan. Saat ini banyak Perguruan Tinggi yang melibatkan dan mengoptimalkan pemanfaatan teknologi informasi dan komunikasi. Perusahaan, organisasi atau instansi pemerintahan memanfaatkan TIK untuk membuat suatu keputusan. Manfaat lain dari teknologi informasi adalah solusi bisnis yang dapat dimanfaatkan oleh perusahaan atau instansi pemerintahan (Rosmalina, 2015). Selain itu, teknologi informasi dapat dimanfaatkan dalam pencapaian tujuan strategi suatu organisasi. Penerapan Tridharma suatu Perguruan Tinggi yang memanfaatkan sistem dan teknologi informasi (SI/TI) juga memiliki alih fungsi dari pelengkap menjadi hal yang paling penting dalam menghasilkan lulusan atau sumber daya manusia yang kompetitif.

Perguruan Tinggi akan dinilai kualitasnya melalui akreditasi. Salah satu syarat agar Perguruan Tinggi tersebut lolos akreditasi dengan nilai yang baik yaitu dengan adanya Blueprint IT sebagai dokumen tata kelola Perguruan Tinggi. Saat ini banyak Perguruan Tinggi yang berkompetisi dalam penyusunan tata kelola SI/TI yang dimiliki guna mencapai Good university governance (Dalimunthe, 2010). Penerapan Good university governance memerlukan peran dan dukungan sistem dan teknologi informasi di dalamnya.

Sebuah Perguruan Tinggi harus memeiliki dan menerapkan perencanaan SI/TI. Tujuan dari perencanaan SI/TI adalah penentuan arah kebijakan dari Perguruan Tinggi tersebut. Perencanaan SI/TI yang dimaksud merupakan perencanaan strategis bisnis maupun sistem informasi. Keselarasan antara perencanaan strategis SI/TI dengan strategi bisnis perguruan tinggi sangat diperlukan. Nilai Perguruan Tinggi akan lebih baik jika mendapatkan dukungan SI/TI yang efektif dan efisien. Perubahan lingkungan bisnis dan persaingan bisnis Perguruan Tinggi yang semakin kompetitif dapat diantisipasi dan diselesaikan dengan melihat kondisi kondisi internal dan eksternal secara objektif melalui perencanaan strategi SI/TI yang dinamis 
dan fleksibel.

Hasil perencanaan strategis SI/TI adalah sebuah cetak biru (blueprint) IT atau biasa disebut peta perjalanan (roadmap). Roadmap dibuat dengan rentang waktu tertentu ( 5 tahun, 10 tahun, 15 tahun, sampai dengan 25 tahun). Isi dari IT Blueprint yaitu pembangunan sistem informasi suatu organisasi atau perusahaan dengan menggunakan rencana strategis yang dimiliki perusahaan tersebut. Isi dari rencana strategis tersebut dijadikan panduan dalam identifikasi kebutuhan sistem informasi yang diperlukan perusahaan.

Institut Teknologi Telkom Purwokerto atau yang biasa disebut ITTP merupakan salah satu Perguruan Tinggi di bidang teknologi yang ada di Jawa Tengah. ITTP yang berlokasi di Jalan D. I. Panjaitan No. 128 merupakan Perguruan Tinggi dengan mengusung atau berbasis ICT Campus. ICT Campus merupakan Perguruan tinggi berbasis teknologi. Terdapat dua aspek dalam ICT yaitu teknologi informasi dan teknologi komunikasi. Hal yang berkaitan dengan dengan proses, penggunaan sebagai alat bantu, manipulsi, dan pengelolaan informasi merupakan bagian dari teknologi informasi. Sedangkan segala sesuatu yang berkaitan dengan penggunaan alat bantu dalam proses mentransfer data dari perangkat yang satu ke lainnya merupakan teknologi komunikasi (Pulungan, 2017). Kegiatan yang dilakukan di ITTP sebagian besar sudah memanfaatkan SI/TI, tetapi dokumentasi perencanaan dan tata kelola SI/TI belum dibuat dengan baik. Kelebihan yang dimiliki ITTP telah memiliki dasar roadmap perencanaan dan pengembangan. Roadmap tersebut berbentuk dokumen rencana strategis dengan rentang waktu lima tahunan. Kekurangannya ITTP belum memiliki IT Blueprint yang berisi perencanaan strategis SI/TI. Oleh karena itu diperlukan pembuatan IT Blueprint sebagai langkah dalam implementasi visi, misi, dan tujuan Perguruan Tinggi dengan memanfaatkan SI/TI agar lebih terarah.

Penelitian yang dilakukan dalam penyusunan rencana strategi sistem beserta teknologi informasi ini dibuat dengan melihat value chain yang kemudian dilakukan analisis SWOTnya untuk mencari rencana strategisnya. Hasil dari penelitian ini berupa kerangka dasar (blueprint) IT di ITTP. Hal tersebut dapat dilakukan dengan identifikasi faktor-faktor penentu kesuksesan yang dimiliki oleh perusahaan. Faktor penentu kesuksesan dalam SWOT terbagi menjadi beberapa yaitu kekuatan dan kelemahan yang ada pada internal perusahaan, serta peluang dan ancaman dari eksternal perusahaan (Blocher E.J., C.H. Kung., Gary, 2007). Penelitian lain menjelaskan bahwa definisi dari analisis SWOT merupakan suatu alat perencanaan strategik yang penting dalam perencanaan yang digunakan untuk perbandingan antara kekuatan dan kelemahan internal perusahaan dengan peluang dan ancaman dari eksternal (Wanti, S. Taufiqurrahman, 2014). Pencapaian rencana suatu perusahaan dalam memberikan kepuasan pelanggan untuk meningkatkan laba memebutuhkan strategi perencanaan yang baik (Haris, 2013). Strategi memiliki konsekuensi yang multifungsi dan multidimensi. Selain itu, di dalam strategi diperlukan perimbangan faktor-faktor baik eksternal dan internal perusahaan (F.R., 2006). Level unit usaha strategis atau produk dan jasa yakni, keunggulan biaya (cost leadership), diferensiasi (differentiation) dan fokus (focus) merupakan penerapan tiga macam strategi bersaing secara umum (S., 2013).

\section{RELATED WORKS / LiTERATURE REVIEW}

Penelitian tentang perumusan strategi penyusunan IT bluperint ini dilakukan dengan menggunakan analisis SWOT. Sebagai penunjang, penelitian ini mereview jurnal yang membahas tentang SWOT analysis for Planned Maintenance Strategy - a case study.

Penelitian ini dapat mendiagnosa arah tindakan pemeliharaan alat - alat di sebuah pabrik dengan menggunakan analisis SWOT (Jasiulewicz-Kaczmarek, 2016). Perbedaan dengan penelitian yang akan dilakukan adalah mengenai perumusan strategi IT blueprint suatu Perguruan Tinggi dengan menggunakan analisis SWOT. Jurnal yang membahas tentang Values on Strategic Planning Process: A research about the Universities in Turkey menjelaskan hasil 
analisis web dengan menganalisis isi dari web suatu dewan Perguruan Tinggi memperoleh fakta bahwa universitas swasta memiliki nilai tambah suatu organisasi yang lebih rendah daripada univesitas negeri (Karadal, Çelik, \& Saygın, 2013). Jurnal tersebut menjadi referensi penelitian yang dilakukan bertujuan agar ITTP sebagai Universitas swasta memiliki nilai lebih dengan menentukan strategi manajemen di dalamnya. Penelitian dengan judul A Rule Based SWOT Analysis Application: A Case Study for Indonesian Higher Education Institution dapat diketahui bahwa aplikasi yang dibuat dapat membantu stakeholder suatu Program Studi dalam menganalisis SWOT dari Program Studi tersebut dengan tingkat akurasi sebesar 80\% (Thamrin \& Pamungkas, 2017). Hal tersebut memiliki perbedaan dengan penelitian yang akan dilakukan yaitu objek penelitian tidak hanya untuk sebuah Program Studi tetapi juga melibatkan seluruh unit / bagian yang terlibat dalam proses bisnis yang ada di ITTP untuk mengetahui sistem dan teknologi informasi manakah yang akan dijadikan prioritas.

\section{METHODS}

Penelitian ini merupakan penelitian dengan mengggunakan metode kualitatif deskriptif. Penelitian ini dilakukan dengan menganalisa faktor - faktor internal yang ada di ITTP. Faktor faktor internal yang dimaksud terdiri dari kekuatan (Strengths) dan kelemahan (Weaknesses) serta faktor eksternal yaitu peluang (Opportunities) dan ancaman (Threats) yang dimiliki dan dihadapi oleh ITTP. Beberapa langkah yang dilakukan dalam pengumpulan data penelitian ini adalah dengan melakukan observasi atau pengamatan langsung pada objek, wawancara yang dilakukan dengan para pemangku kepentingan yang memahami kondisi ITTP, dan dokumentasi dengan menganalisa renstra yang telah dibuat ITTP.

Teknik yang digunakan untuk mengolah data dalam penelitian ini menggunakan teknik analisis interpretif yang mengacu pada kata - kata maupun kalimat yang disesuaikan dengan dasar teori terkait. Analisis ini untuk menjelaskan dari hasil analisa kualitatif yang berupa data deskriptif. Beberapa langkah teknik analisa data yang dilakukan dalam penelitian ini adalah dengan mengumpulkan data kemudian menganalisa semua data yang diberikan oleh ITTP. Data yang dimaksud berupa profil perusahaan, unit - unit yang ada di ITTP dengan deskripsi tugas dan wewenangnya, fasilitas dan jenis pelayanan dari masing - masing unit, sumber daya dan faktor pendukung lain yang dimiliki oleh masing - masing unit. Langkah kedua adalah dengan menganalisa sumber daya yang ada di ITTP dengan cara melakukan perbandingan antara faktor internal (kekuatan dan kelemahan) dengan faktor eksternal (peluang dan ancaman) ITTP. Perbandingan tersebut dilakukan dengan membuat matriks SWOT. Langkah ketiga yaitu dengan melakukan identifikasi variabel - variabel pembuatan keunggulan yang kompetitif pada ITTP yaitu berupa strategi yang dapat digunakan dalam pengembangan ITTP dengan melihat sistem informasi mana yang dapat dijadikan fokus dan prioritas pengembangan. Langkah terakhir yaitu dengan membuat kesimpulan dan saran.

\section{RESULTS AND DiSCUSSION}

ITTP merupakan salah satu lembaga di bidang pendidikan di bawah naungan Telkom Group. Awalnya ITTP bernama Akademi Telkom (Akatel) kemudian mengalami perkembangan menjadi Sekolah Tinggi Teknologi Telematika Telkom (ST3 Telkom) Purwokerto. Pada bulan Agustus 2017 berubah menjadi Institut Teknologi Telkom Purwokerto (ITTP). ITTP merupakan institut pertama kali di Jawa Tengah yang berfokus pada bidang ICT. ITTP yang berlokasikan di Jalan D.I. Panjaitan No. 128 juga terus dan selalu berusaha untuk mengembangkan dan meningkatkan kualitas pendidikan dan layanannya.

Saat menjadi ST3, ITTP sudah memiliki blueprint, dengan beralih status menjadi ITTP, maka diperlukan pula pembuatan blueprint terbaru. Hal tersebut dikarenakan proses bisnis yang ada di dalam institusi juga mengalami perubahan. Pembuatan blueprint diperlukan untuk masa depan institusi, karena blueprint berisi tentang kerangka kerja dari ITTP. Selain itu, penyusunan 
blueprint dilakukan untuk menghadapi tantangan - tantangan yang ada karena semakin bertambahnya pesaing atau lembaga di bidang pendidikan.

Langkah yang dilakukan pertama kali setelah data masing - masing terkumpul, maka dilakukan analisis. Strength dan Weaknesses dikelompokkan berdasarkan masing - masing unit seperti Tabel 3.1 hingga Tabel 3.5.

Tabel 3.1.

Tabel Strength dan Weaknesses Unit Prodi

\begin{tabular}{|c|c|}
\hline Strengths & Weaknesses \\
\hline $\begin{array}{l}\text { 1. Pada penyusunan dokumen kurikulum } \\
\text { diadakan workshop yang mengundang }\end{array}$ & $\begin{array}{l}\text { 1. Tingkat awareness dosen terhadap tertib } \\
\text { administrasi pembelajaran masih rendah }\end{array}$ \\
\hline narasumber eksternal & 2. Mekanisme \\
\hline 2. Kurikulum disusun oleh tim kurikulum & pembelajaran \\
\hline $\begin{array}{l}\text { 3. Dalam penyusunan RPS diadakan } \\
\text { workshop penyusunan RPS }\end{array}$ & $\begin{array}{l}\text { dengan proses validasi dengan unit lain } \\
\text { 3. Kesiapan infrastruktur IT dalam mendukung } \\
\text { proses pembelajaran masih rendah/terbatas. }\end{array}$ \\
\hline
\end{tabular}

Tabel 3.2 Strength dan Weaknesses Unit LPPM

\begin{tabular}{ll}
\hline \multicolumn{1}{c}{ Strengths } & \multicolumn{2}{c}{ Weaknesses } \\
\hline $\begin{array}{l}\text { 1. Pada penyusunan dokumen kurikulum } \\
\text { diadakan workshop yang mengundang } \\
\text { narasumber eksternal }\end{array}$ & $\begin{array}{l}\text { 1. Belum ada kurikulum yang memuat } \\
\text { pengembangan kompetensi mahasiswa ke } \\
\text { masyarakat. }\end{array}$ \\
$\begin{array}{ll}\text { 2. Kurikulum disusun oleh tim kurikulum } \\
\begin{array}{l}\text { 3. Dalam penyusunan RPS diadakan } \\
\text { workshop penyusunan RPS }\end{array} & \begin{array}{l}\text { Belum ada kebijakan yang mengatur riset } \\
\text { grup tetapi ada beberapa prodi yang sudah } \\
\text { menjalankan riset grup. }\end{array} \\
\text { 3. Belum ada sistem untuk data penelitian. }\end{array}$ \\
\hline
\end{tabular}

Tabel 3.3

Tabel Strength dan Weaknesses Unit SDM

\begin{tabular}{ll}
\hline \multicolumn{1}{c}{ Strengths } & \multicolumn{1}{c}{ Weaknesses } \\
\hline $\begin{array}{l}\text { 1. Sudah ada bentuk dukungan dari yayasan } \\
\text { terkait peningkatan kompetensi dosen dan } \\
\text { karyawan }\end{array}$ & $\begin{array}{c}\text { 1. Belum ada perencanaan kebutuhan jumlah } \\
\text { dosen dengan pertumbuhan mahasiswa baru }\end{array}$ \\
$\begin{array}{ll}\text { 2. Pelaksanaan untuk peningkatan kompetensi } \\
\text { Adanya aturan yang mengatur remunerasi } \\
\text { berbasis kinerja yang dibuat oleh } \\
\text { yayasan, berdasarkan : kinerja terbaik dan }\end{array}$ & $\begin{array}{l}\text { baik oleh pihak SDM } \\
\text { publikasi ilmiah }\end{array}$ \\
\hline
\end{tabular}

Tabel 3.4

Tabel Strength dan Weaknesses Unit Perpustakaan

\begin{tabular}{lllll}
\hline \multicolumn{4}{c}{ Strengths } & \multicolumn{2}{c}{ Weaknesses } \\
\hline $\begin{array}{l}\text { 1. Sudah adanya bentuk dukungan dari } \\
\text { institusi }\end{array}$ 1. Belum adanya pengelolaan jurnal untuk \\
pengadaan/procurement di lingkungan & $\begin{array}{l}\text { 2. Bersi softcopy. } \\
\text { mengelola plagiarisme. }\end{array}$ & \\
perpustakaan. & kegiatan & \\
2. Adanya sistem evaluasi dan perbaikan & & \\
terhadap kritik dan saran dari pengunjung & & \\
yang dilakukan oleh pihak perpustakaan & & \\
3. Data keterlambatan pengembalian buku \\
sudah terekam oleh sistem
\end{tabular}




\begin{tabular}{llll}
\hline \multicolumn{3}{c}{ Strengths } & \multicolumn{3}{c}{ Weaknesses } \\
\hline $\begin{array}{l}\text { 1. Kualitas SDM IT Support sudah } \\
\text { memenuhi kompetensi sesuai tupoksi } \\
\text { masing-masing. }\end{array}$ & $\begin{array}{l}\text { 1. Load kerja bagian IT Support belum } \\
\text { seimbang dengan jumlah SDM yang } \\
\text { tersedia. }\end{array}$ \\
$\begin{array}{l}\text { 2. Sudah ada bentuk dukungan dari institusi } \\
\text { terkait dengan peningkatan kompetensi }\end{array}$ & $\begin{array}{l}\text { 2. Belum adanya kegiatan perencanaan terkait } \\
\text { dengan kebutuhan di bagian IT Support }\end{array}$ \\
$\begin{array}{l}\text { SDM di IT Support. } \\
\text { 3. Sudah ada kesesuaian pengembangan } \\
\text { aplikasi dengan proses bisnis internal }\end{array}$ & & \\
\hline
\end{tabular}

Data Opportunity dibuat secara umum mencakup dari semua unit yang ada di ITTP, antara lain:

1. Standarisasi proses pendidikan tinggi di ITTP sudah dalam tahap pengembangan, sehingga ini menjadi kesempatan bagi ITTP untuk mengembangkan target berikut dari institusi menjadi Universitas

2. Sistem penjaminan mutu di ITTP menjadi acuan institusi untuk memenuhi standar mutu pendidikan secara konsisten dan berkelanjutan, dan juga Institusi menjamin agar lulusan sesuai dengan kompetensi yang dijanjikan. secara continuous, ini menjadi sebuah opportunity bagi institusi untuk lebih memperluas "brand" nya di Indonesia maupun di luar negeri

3. Kegiatan pelaporan kinerja proses belajar mengajar di tiap akhir semester menjadi keuntungan bagi ITTP karena ini sebagai self evaluation, data pendukung untuk akreditasi BAN-PT maupun dalam program hibah kompetisi

4. Pertumbuhan ekonomi yang terus meningkat di Indonesia diharapkan ITTP dapat terus menumbuhkan minat pendidikan di seluruh Indonesia.

Selain itu, data Threat yang didapatkan juga dijadikan satu secara umum, yaitu:

1. Dosen yang ada di IT Telkom Masih banyak yang belum memenuhi standar kualifikasi dosen seperti contoh: Masih banyak dosen yang belum mendapatkan NIDN, masih belum mendapatkan sertifikasi dosen, dan masih banyak dosen yang belum mendapatkan jabatan fungsional akademik.

2. ITTP sampai sekarang masih mengerjakan dalam hal peningkatan kualitas penyelenggaraan pendidikan

3. Penyelenggaraan kurikulum pendidikan di ITTP masih dalam pengembangan karena beberapa prodi belum ada sebuah kurikulum acuan dalam penyelenggaraan kurikulum pendidikannya.

Setelah data - data tersebut diolah maka didapatkan matrix SWOT strategi bisnis internal dan eksternal ITTP yang dapat dilihat pada Tabel 3.6. 


\begin{tabular}{|c|c|c|c|c|}
\hline No & Strengths & Weaknesses & Opportunity & Threats \\
\hline 1. & $\begin{array}{l}\text { Sudah ada bagian / } \\
\text { biro khusus yang } \\
\text { menangani } \\
\text { teknologi informasi } \\
\text { yaitu unit IT } \\
\text { Support }\end{array}$ & $\begin{array}{l}\text { Belum adanya } \\
\text { topologi data center } \\
\text { yang mengacu pada } \\
\text { suatu standar }\end{array}$ & $\begin{array}{l}\text { Ketertarikan } \\
\text { donator dan sponsor } \\
\text { terhadap profesi } \\
\text { yang dihasilkan }\end{array}$ & $\begin{array}{l}\text { Sistem } \\
\text { Penjaminan Mutu } \\
\text { yang ada belum } \\
\text { terintegrasi dengan } \\
\text { sistem pelaporan } \\
\text { EPSBED }\end{array}$ \\
\hline 2. & $\begin{array}{lr}\text { Sudah } & \text { terdapat } \\
\text { SOP operasional } \\
\text { dalam } 6 \quad \text { (enam) } \\
\text { Prosedur Standar } \\
\text { Mutu (PSM) yang } \\
\text { terdapat di tiap - } \\
\text { tiap unit. }\end{array}$ & $\begin{array}{ll}\text { Belum adanya } \\
\text { fasilitas DC dan } \\
\text { SRC untuk data } \\
\text { center }\end{array}$ & \begin{tabular}{l}
\multicolumn{2}{l}{ Perkembangan } \\
teknologi yang \\
semakin fleksibel \\
karena mencakup \\
semua device untuk \\
mobilitas r dan \\
aksesibilitas
\end{tabular} & $\begin{array}{l}\text { Belum adanya } \\
\text { standar tata kelola } \\
\text { TI dan keamanan } \\
\text { sistem informasi } \\
\text { seperti ISO } 20000 \\
\text { dan ISO } 27001\end{array}$ \\
\hline 3. & & & $\begin{array}{l}\text { Kebutuhan IS / IT } \\
\text { yang meningkat } \\
\text { pada semua bidang }\end{array}$ & \\
\hline 4. & & & $\begin{array}{l}\text { Adana aplikasi I- } \\
\text { Gracias dari Telkom } \\
\text { University }\end{array}$ & \\
\hline 5. & & & $\begin{array}{lr}\text { Adanya } & \text { arsitektur } \\
\text { standar } & \text { SOA } \\
\text { (Service } & \text { Oriented } \\
\text { Archiecture) }\end{array}$ & \\
\hline
\end{tabular}

Berdasarkan hasil penelitian yang dilakukan dapat diketahui bahwa untuk menjadi Good university governance diperlukan tata kelola dalam semua unit yang terlibat. Hal tersebut sesuai dengan jurnal tentang tatakelola universitas menuju Good university governance (Dalimunthe, 2010). Hasil penelitian tersebut menunjukkan bahwa ITTP secara tidak langsung siap menuju Good university governance. ITTP telah memiliki blueprint yang dapat dijadikan pedoman dalam pengembangan dan peningkatan kualitas. Selain itu dengan mengetahui kekuatan, kelemahan, peluang dan ancaman dari dalam dan luar ITTP juga menjadi alasan bahwa institut tersebut dinyatakan siap dalam menghadapai persaingan yang kompetitif. Blueprint ITTP dibuat dengan melakukan analisis SWOT yang sesuai untuk mementukan kesuksesan perusahaan(Blocher E.J., C.H. Kung., Gary, 2007).

\section{Conclusions}

Blueprint suatu institusi penting dan harus dibuat untuk mempersiapkannya menghadapi persaingan yang semakin kompetitif. Pembuatan blueprint dapat dilakukan dengan menganalisa faktor - faktor penentu baik yang berasal dari internal maupun eksternal institusi. Analisa yang sesuai dalam penentuan faktor - faktor penentu dalam pembuatan blueprint adalah menggunakan analisa SWOT yang dilakukan dengan menganalisa Strengths (Kekuatan) dan Weaknesses (Kelemahan) internal intitusi serta Opportunity (Peluang) dan Threaths (Ancaman) yang berasal dari luar institusi 


\section{REFERENCES}

[1] Blocher E.J., C.H. Kung., Gary, dan T. W. L. (2007). Manajemen Biaya: Penekanan Strategis. Jakarta: Salemba Empat.

[2] Dalimunthe, R. (2010). Analisis persepsi karyawan bagian administrasi umum tentang penerapan prinsip Good Corporate Governance (transparansi, akuntabilitas, keadilan, dan partisipasi) kaitannya dengan kinerja karyawan di Rumah sakit Umum Daerah dr.Zainoel Abidin Banda Aceh, 1-7.

[3] F.R., D. (2006). Manajemen Srategis. Edisi Sepuluh. Jakarta: Salemba Empat.

[4] Haris, A. (2013). Pengembangan Produk Unggulan Industri Kecil dan Strategi Pemasaran Berbasis Analisis SWOT. Jurnal EcoBuss, 1(1).

[5] Jasiulewicz-Kaczmarek, M. (2016). SWOT analysis for Planned Maintenance strategy-a case study. IFAC-PapersOnLine, 49(12), 674-679. https://doi.org/10.1016/j.ifacol.2016.07.788

[6] Karadal, H., Çelik, C., \& Saygın, M. (2013). Corporate Values on Strategic Planning Process: A Research about the Universities in Turkey. Procedia - Social and Behavioral Sciences, 99, 762-770. https://doi.org/10.1016/j.sbspro.2013.10.548

[7] Pulungan, S. (2017). Pemanfaatan ICT Dalam Pembelajaran PAI QUERY : Jurnal Sistem Informasi, 5341(April), 19-24.

[8] Rosmalina. (2015). Model Rencana Strategis Sistem Informasi di Univ Bale Bandung. PhD Proposal, 1. https://doi.org/10.1017/CBO9781107415324.004

[9] S., M. (2013). Manajemen Stratejik. Yogyakarta: YKPN.

[10] Thamrin, H., \& Pamungkas, E. W. (2017). A Rule Based SWOT Analysis Application: A Case Study for Indonesian Higher Education Institution. Procedia Computer Science, 116, 144-150. https://doi.org/10.1016/j.procs.2017.10.056

[11] Wanti, S. Taufiqurrahman, dan D. D. R. (2014). Analisis Strategi Keunggulan bersaing dengan pendekatan Analisis SWOT pada Spartan Gym Pekanbaru. JOM Vekon 1(2). 